\title{
Comment on "Noble gases and stable isotopes in a shallow aquifer in southern Michigan: Implications for noble gas paleotemperature reconstructions for cool climates" by Chris M. Hall et al.
}

\author{
Stephan Klump, ${ }^{1,2}$ Matthias S. Brennwald, ${ }^{1}$ and Rolf Kipfer ${ }^{1,3}$ \\ Received 24 July 2006; revised 20 October 2006; accepted 31 October 2006; published 22 December 2006.
}

Citation: Klump, S., M. S. Brennwald, and R. Kipfer (2006), Comment on "Noble gases and stable isotopes in a shallow aquifer in southern Michigan: Implications for noble gas paleotemperature reconstructions for cool climates" by Chris M. Hall et al., Geophys. Res. Lett., 33, L24403, doi:10.1029/2006GL027496.

[1] Hall et al. [2005] present a comprehensive, stimulating and controversial set of noble gas data from a shallow, unconfined, sandy aquifer in Ann Arbor, Michigan. This data set comprises a time series of about 270 days starting in October 2004. The authors determined the noble gas temperature (NGT) from the measured noble gas concentrations. NGTs were found to be consistently lower than the mean annual air temperature (MAAT) of $9.1^{\circ} \mathrm{C}$, whereas the MAAT agrees with the measured in situ groundwater temperature. Because of this agreement, we can assume that the mean annual soil temperature (MAST) corresponds closely to the MAAT. Hall et al. [2005] developed several concepts to explain the deviation between the NGT and MAAT. However, they could not find a conclusive solution to the problem and conclude that further studies are needed to assess and identify the relevant mechanisms.

[2] Here we show that NGT and MAST do not need to be equal. We will present additional hypotheses which we consider to give reasonable and convincing explanations for the data, and which were not explored by Hall et al. [2005].

[3] In a strict physical sense, the NGT, which is derived from the concentrations of dissolved atmospheric noble gases, is identical to the water temperature that prevailed during the last gas/water partitioning. In groundwater, this corresponds to the temperature at which gas exchange occurred at the groundwater table during recharge. In many cases, the thickness of the unsaturated zone exceeds several meters. In these cases, the soil temperature at the groundwater table shows little seasonal variation and corresponds closely to the MAAT [Stute and Schlosser, 1993], unless the land cover introduces a systematic offset between MAST/ NGT and MAAT [Stute and Sonntag, 1992]. In the case of a shallow unsaturated zone, however, the seasonal tempera-

\footnotetext{
${ }^{1}$ Department of Water Resources and Drinking Water, Swiss Federal Institute of Aquatic Science and Technology, Dübendorf, Switzerland.

${ }^{2}$ Also at Institute of Biogeochemistry and Pollutant Dynamics, ETH Zurich, Zurich, Switzerland.

${ }^{3}$ Also at Institute of Isotope Geochemistry and Mineral Resources, ETH Zurich, Zurich, Switzerland.
}

ture fluctuation at the groundwater table can amount to several Kelvin. Assuming a typical thermal diffusivity for sandy soils of $D_{\text {th }}=0.1 \mathrm{~m}^{2} \mathrm{~d}^{-1}$, temperature variations detectable by variations in noble gas concentrations are present down to soil depths of about $10 \mathrm{~m}$ [e.g., Hillel, 2003; Stute and Schlosser, 1993], i.e., the annual amplitude of soil temperature variation is about $8^{\circ} \mathrm{C}$ at $2 \mathrm{~m}$ depth, $3^{\circ} \mathrm{C}$ at $5 \mathrm{~m}$ depth, and $1{ }^{\circ} \mathrm{C}$ at $10 \mathrm{~m}$ depth.

[4] The NGT of groundwater samples therefore represents a mean of the changing soil temperature weighted by the recharge rate. As a result, the NGT would be lower than the MAAT (or MAST) if recharge occurs predominantly during the cold season [e.g., Beyerle et al., 1999].

[5] Land cover has to be excluded as an explanation for the observed differences between NGTs and MAAT, because the measured groundwater temperature is virtually identical to the MAAT. The geometrical information on the sampling well of Hall et al. [2005] is ambiguous (depth of well, depth of groundwater table, position of screen). Furthermore, no information is given on the thickness of the unsaturated zone within the catchment area of the well, or on the local recharge rate and its seasonal variability. However, groundwater-level data available from the Michigan Groundwater Mapping Project (http://gwmap. rsgis.msu.edu) show that the thickness of the unsaturated zone in the vicinity of the sampling well is partly less than 5 to $10 \mathrm{~m}$.

[6] Well hydrographs from shallow aquifers in Michigan (http://nwis.waterdata.usgs.gov) show a recurrent annual rise in the groundwater tables from autumn until spring, with a maximum during spring. After this rise, groundwater levels drop back to a minimum in autumn. The groundwater table rise during winter and spring indicates that most of the recharge occurs during the cold season, when soil temperature in the shallow subsurface is significantly lower than the MAAT. In fact, the stable isotope data presented by Hall et al. [2005] show a considerable recharge component during snow melt as all samples indicate a mixture of $\gtrsim 30 \%$ melt water and $\$ 70 \%$ rain water.

[7] The seasonality of groundwater recharge is further indicated by the seasonal variation in the excess air component (Figure 1). Since the formation of excess air is usually closely connected to groundwater recharge and groundwater table fluctuations [Holocher et al., 2002], the strong excess air variation indicates a pronounced seasonality of local recharge.

[8] In summary, the above discussion shows that the NGT at the study site can indeed be expected to be lower than MAAT and MAST due to its weighting by the recharge rate, which is highest during the cold season. Furthermore, 


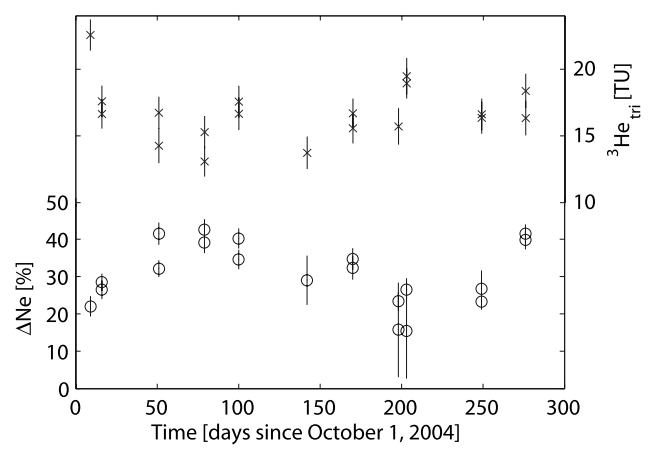

Figure 1. Ne excess with respect to the atmospheric equilibrium concentration $(\Delta \mathrm{Ne})$ and ${ }^{3} \mathrm{He}_{\text {tri }}$ as a function of time. $\Delta \mathrm{Ne}$, which reflects the excess air component in the groundwater, and ${ }^{3} \mathrm{He}_{\text {tri }}$ were estimated from the reprocessed data of Hall et al. [2005] using the closed-system equilibration model of Aeschbach-Hertig et al. [2000]. $\Delta \mathrm{Ne}$ shows a significant seasonal variability, indicating local seasonality of recharge. ${ }^{3} \mathrm{He}_{\text {tri }}$ seems to follow a similar seasonal variation.

the possibility of a deviation between NGT and MAAT or MAST is further demonstrated by recent field experiments. We analyzed the noble gas concentrations of seepage water sampled from a shallow unsaturated zone (S. Klump et al., Field experiments yield new insights into gas exchange and excess air formation in natural porous media, submitted to Geochimica et Cosmochimica Acta, 2006). The NGTs of these samples correspond closely to the in situ soil temperatures at the date of sampling. The soil temperature, however, shows a seasonal variation, and the NGTs therefore differed significantly from MAAT and MAST. To us, the weighting of the NGT by the recharge rate therefore seems a reasonable and natural explanation for the difference in the NGT and the MAAT or MAST observed by Hall et al. [2005].

[9] Similarly, we would like to present a more natural explanation for the ${ }^{3} \mathrm{He}$ and ${ }^{4} \mathrm{He}$ results found by Hall et al. [2005]. The authors observed ${ }^{3} \mathrm{He}$ and ${ }^{4} \mathrm{He}$ excesses in all groundwater samples and concluded that the partial pressures of both $\mathrm{He}$ isotopes in the soil air close to the groundwater table must exceed those in the free atmosphere. From the amount of He excess, the authors estimate that the soil air at the groundwater table remains out of atmospheric equilibrium for years to decades. However, a simple estimate of the characteristic diffusion length of $\mathrm{He}$ in porous media calls this conclusion into question. The diffusion length of He is $x=\sqrt{2 D t}$ [Einstein, 1905], where $D=D_{0} \cdot \epsilon^{4 / 3}$ is the effective $\mathrm{He}$ diffusivity in the unsaturated zone [Millington, 1959], $D_{0}=6 \cdot 10^{-5} \mathrm{~m}^{2} \mathrm{~s}^{-1}$ is the He diffusivity in free air, and $\epsilon=0.4$ is a typical value for the gas-filled porosity. For an unsaturated-zone depth of less than $20 \mathrm{~m}$ (i.e. $x<20 \mathrm{~m}$ ), the characteristic time scale $t$ of diffusive He exchange between atmosphere and groundwater is therefore less than about 4 months. Although groundwater that has accumulated considerable amounts of radiogenic He may act in principle as a source of radiogenic He in the unsaturated zone, the fast diffusion in the gas phase with respect to that in groundwater $\left(D_{\text {soilair }} \gg D_{\text {water }}\right)$ will prevent any observable increase in the partial pressure of $\mathrm{He}$ in shallow unsaturated zones. Hence, the He partial pressure at the groundwater table is unlikely to remain out of equilibrium with the atmosphere on time scales of years to decades as put forward by Hall et al. [2005].

[10] Hall et al. [2005] assert that the accumulated amount of radiogenic ${ }^{4} \mathrm{He}$ suggests a groundwater residence time of about 30 years. From our point of view, the observed amounts of accumulated tritiogenic ${ }^{3} \mathrm{He}$ can also be consistently understood in terms of groundwater residence time. Although no ${ }^{3} \mathrm{H}$ measurements in the groundwater at the study site are available, the atmospheric ${ }^{3} \mathrm{H}$ input and the ${ }^{3} \mathrm{He}$ excess can be used to estimate the groundwater residence time at $\sim 25$ years (Figure 2 ).

[11] Also, Hall et al. [2005] argue that the sample taken immediately following a major snow melting event shows the influx of modern water reflected by low values of $\delta^{18} \mathrm{O}$ and $\delta^{2} \mathrm{H}$. Hall et al. [2005] further claim that this is in disagreement with the significant and constant He excess observed in all samples. They therefore conclude that "these gases are not in equilibrium with the atmosphere". However, we disagree on this conclusion because the sample with low stable isotope values was taken on February 15, and Hall et al. [2005] do not provide any He data from this date. Instead, the next sample with available He data was taken on February 20 showing a similar amount of $\mathrm{He}$ excess as all other samples. This is not surprising as the stable isotope sample taken on February 19 also shows $\delta^{18} \mathrm{O}$ and $\delta^{2} \mathrm{H}$ values that are heavier than those of the sample from February 15 and similar to all other samples, again.

[12] It has to be noted that all samples represent a mixture of waters with different residence times, even the one sample which was taken immediately following a snow melting event and which might indicate a significant portion of very young groundwater. This applies especially to wells with large screen lengths of several meters because mixing predominantly occurs in the well and not within the aquifer. The fast diffusion of $\mathrm{He}$ in the unsaturated zone, the agreement of radiogenic ${ }^{4} \mathrm{He}$ and tritiogenic ${ }^{3} \mathrm{He}$ in terms of groundwater residence time, and the incomplete He data set challenge the explanation put forward by Hall et al. [2005] that the soil air might be enriched in He.

[13] The hypotheses of $\mathrm{He}$ enrichment and $\mathrm{O}_{2}$ depletion, as well as the negative pressure model, could be assessed directly by analyzing the composition and relative humidity

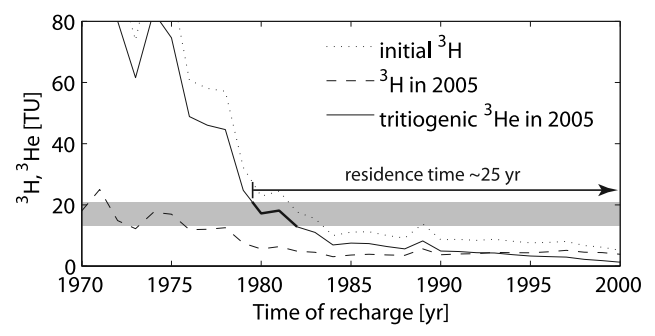

Figure 2. Atmospheric ${ }^{3} \mathrm{H}$ input, remaining ${ }^{3} \mathrm{H}$ due to decay, and accumulated tritiogenic ${ }^{3} \mathrm{He}$ in groundwater relative to the time of recharge. Figure 2 shows the ${ }^{3} \mathrm{H}$ input function for Chicago, which has been extended by correlation with the ${ }^{3} \mathrm{H}$ input function for Vienna (data available at http://isohis.iaea.org). The gray bar indicates the range of the ${ }^{3} \mathrm{He}$ excess in the data of Hall et al. [2005] due to ${ }^{3} \mathrm{H}$ decay, calculated using the closed-system equilibration model of Aeschbach-Hertig et al. [2000]. 
of the soil air. Hall et al. [2005] report that all noble gas isotope ratios, with the exception of $\mathrm{He}$, are identical to those in the free atmosphere. This contradicts the diffusion model. If this model was applicable, the isotope ratios should be fractionated, i.e., the groundwater should be depleted in the lighter isotopes of these elements due to their larger diffusivities (relative deviations from the atmospheric equilibrium values: $0.7-3 \%$ for ${ }^{20} \mathrm{Ne} /{ }^{22} \mathrm{Ne}$, $0.2-1.4 \%$ for ${ }^{40} \mathrm{Ar}{ }^{36} \mathrm{Ar}$ ). Typical measurement errors for $\mathrm{Ne}$ and $\mathrm{Ar}$ isotope ratios are less than $0.5 \%$ and fractionation should therefore be observable in the data. Otherwise, the diffusion model has to be rejected.

[14] Hall et al. [2005] present a stimulating set of noble gas concentrations in groundwater that touches on crucial issues of gas/water partitioning in porous media. However, we believe that the hypotheses provided by the authors to elucidate the differences between NGTs and MAAT, as well as the observed $\mathrm{He}$ excess, are incomplete and debatable. From our point of view, seasonally variable groundwater recharge and groundwater mixing (in the well) provide a more realistic and physically more appropriate framework to explain the data.

\section{References}

Aeschbach-Hertig, W., F. Peeters, U. Beyerle, and R. Kipfer (2000), Paleotemperature reconstruction from noble gases in ground water taking into account equilibration with entrapped air, Nature, 405, 1040-1044.
Beyerle, U., W. Aeschbach-Hertig, M. Hofer, D. M. Imboden, H. Baur, and R. Kipfer (1999), Infiltration of river water to a shallow aquifer investigated with ${ }^{3} \mathrm{H} /{ }^{\beta} \mathrm{He}$, noble gases and CFCs, J. Hydrol., 220, 169-185.

Einstein, A. (1905), Über die von der molekularkinetischen Theorie der Wärme geforderte Bewegung von in ruhenden Flüssigkeiten suspendierten Teilchen, Ann. Phys., 17, 549-560.

Hall, C.M., M.C. Castro, K.C. Lohmann, and L. Ma (2005), Noble gases and stable isotopes in a shallow aquifer in southern Michigan: Implications for noble gas paleotemperature reconstructions for cool climates, Geophys. Res. Lett., 32, L18404, doi:10.1029/2005GL023582.

Hillel, D. (2003), Introduction to Environmental Soil Physics, Elsevier, New York.

Holocher, J., F. Peeters, W. Aeschbach-Hertig, M. Hofer, M. S. Brennwald, W. Kinzelbach, and R. Kipfer (2002), Experimental investigations on the formation of excess air in quasi-saturated porous media, Geochim. Cosmochim. Acta, 66, 4103-4117.

Millington, R. J. (1959), Gas diffusion in porous media, Science, 130 $100-102$.

Stute, M., and P. Schlosser (1993), Principles and applications of the noble gas paleothermometer, in Climate Change in Continental Isotopic Records, Geophys. Monogr. Ser., vol. 78, edited by P. K. Swart, et al., pp. 89-100, AGU, Washington, D. C.

Stute, M., and C. Sonntag (1992), Palaeotemperatures derived from noble gases dissolved in groundwater and in relation to soil temperature, in Isotopes of Noble Gases as Tracers in Environmental Studies, pp. 111-122, Int. At. Energy Agency, Vienna.

M. S. Brennwald, R. Kipfer, and S. Klump, Department of Water Resources and Drinking Water, Eawag, Überlandstrasse 133, CH-8600 Dübendorf, Switzerland. (stephan.klump@eawag.ch) 